\title{
Reply to Oaklander
}

\section{Lynne Rudder Baker}

\author{
University of Massachusetts Amberst \\ Department of Philosophy \\ Amberst, Massachusetts \\ U.S.A. \\ lrbaker@philos.umass.edu
}

Article info

CDD: 115

Received: 01.03.2017; Accepted: 14.03.2017

DOI: http://dx.doi.org/10.1590/0100-6045.2017.V40N1.LB

Keywords

The Metaphysics of Everyday Life

A- and B-theories of time

Nathan Oaklander

Transiency

\begin{abstract}
In September, 2016, I replied to an earlier draft of Oaklander's Critique of my view of time for Manuscrito. Now he has published an extremely complex 50-page expanded version. There is no way that a reply in a journal could cover all the topics Oaklander discusses. So, I will stick mainly to my own view to which Oaklander was responding.

My reply is in two parts. In the first, directed at Oaklander's earlier draft, I say what I want to do in philosophy in general, and in the philosophy of time in particular. In the second part, I mention some places where he (apparently) misunderstands my view.
\end{abstract}

\section{Part I}

First, let me thank Prof. Oaklander for writing so lengthily and seriously about my view of time.

Second, let me say what I am trying to do in philosophy. I am trying to construct an ontology that makes sense of the world as we interact with it. The world as we interact with it, I claim (uncontroversially, I would have thought), is characterized by past, present, future, with the present as

Manuscrito - Rev. Int. Fil. Campinas, v. 40, n. 1, pp. 67-73, jan.-mar. 2017. 
privileged. But these A-series features of reality as we experience it, if I am right, are not independent of the B-series. The B-series is fundamental: it has existed as long as the universe has; the A-series is a product of selfconscious beings: Our consciousness is structured in such a way that we experience reality in terms of past, present and future. There was no Aseries a million years ago.

Since I take the B-series to be fundamental to time, and endorse a theory that recognizes both the A- and the B-series as having ontological status, I want to insure that the A-series is a genuine aspect of time. I say, "It is an important feature of time that it has a disposition toward Aproperties, which are manifest only in relation to self-conscious beings....The B-series alone renders too many temporal facts invisible." (The Metaphysics of Everyday Life (2007),154)

Prof. Oaklander criticizes my taking past, present and future and so on to be properties, A-properties. My commitment to A-properties is a matter of my being a realist about both the A- and the B-series. Nothing I say has to do with Russell or Broad or Grünbaum, or for that matter, McTaggart. (Since he denied the existence of time altogether, McTaggart is less than helpful. (p. 11).) To say that there are (irreducible) A-properties is one way to say that the A-series has ontological status-even though its existence depends on there being creatures like us. (On my view, the mind-dependence of the A-series is irrelevant to its ontological status.)

Many of Prof. Oaklander's criticisms (e.g., comments on Russell and some on Grünbaum) by-pass what interests me. He says that I misunderstand the R-theory, but I never mentioned any R-theory, and it plays no role in my view of time. I'm confident I understand the B-theory as Grünbaum construed it. (Unlike me, Grünbaum thought that the Atheory had no ontological significance.) Moreover, many of Prof. Oaklander's worries-e.g., those about coming into existence, growth, and absolute becoming-seem to rest on A-theory claims that I reject.

I think that I see where the "disconnect" between us is. I think that Prof. Oaklander appears to take a temporal relation to be a "dynamic relation, involv[ing] transition from one event to the next." (p.13) This understanding of temporality clearly presupposes the A-series. Physical time (B-series) is dense; between any two events there is another event. Hence, on the B-theory, there is no next event. If I am right that Prof. 
Oaklander's understanding of temporality presupposes the A-series, this would explain why he keeps asking whether in my view B-facts are temporal or not.

Here's what I would say: The B-series relation between the Lisbon earthquake and the signing of the Declaration of Independence is temporal: The former precedes the latter, and 'precedes' is a temporal verb. So, Prof. Oaklander may respond: When did this relation come into existence? That seems to me a trivial question, but if you insist on an answer, here it is: the relation comes into existence when the later event occurs.

Perhaps because of his A-theory proclivities, Prof. Oaklander seems to use the term 'temporal' equivocally. On one use of 'temporal' (in the Atheorist's sense of involving a transition) B-relations are nontemporal; but on another use of 'temporal', B-relations are temporal in that their relata exist in time. But there is no contradiction here, just use of the term 'temporal' in different ways for different things, relations and their relata.

The question, "Which time is now?" (p. 9) rests on a kind of category mistake. If there is self-consciousness, almost every time is now (A-series) at some time or other (B-series). Each moment that someone is aware of something is now when she is aware of it; perhaps we should say, "That time is now for her then." (I do not have an analysis of tense in terms of date. I have no analysis of anything. Dates provide a convenient way of distinguishing one time from another.)

Prof. Oaklander's concerns about grounding seem beside the point. Of course, consciousness cannot "ground" the coming into existence of conscious beings, but evolution can. (p. 14) The discussion of a "ground of irreducible B-relational facts" and a "vicious infinite regress" and when B-facts come into existence (p. 12) make little sense to me. Prof. Oaklander says: "If the objects that begin to exist in the future come into existence or become present Baker cannot ground their becoming in an absolute sense, and so there is no ontological diversity." (p. 13) What does it mean to "ground becoming in an absolute sense"? And why does Prof. Oaklander assume that there is a dichotomy between " $\mathrm{R}$-theoretic becoming" (whatever that is) and "absolute becoming."? I think that there are A-series notions ('absolute becoming'?) floating around that are 
extraneous. In any case, such terms play no role in my view, and Prof. Oaklander has given me no reason to think that they should.

Nowadays time is discussed as a controversy between eternalism and presentism. As I said, I do not think that either of these is adequate. I start with Grünbaum (but I don't stick with him for long), where the issue is between mind-independence and mind-dependence. I have never accepted the idea that our experience of the present can be understood reductively, and I have argued at some length against indexical (reflexive) theories of nowness.

When I discuss "being in the Domain," I am talking about the scope of the unrestricted existential quantifier. I am not talking about eternalism. (And I never refer to R-theory.) The Domain comprises all objects that ever exist at any time; it doesn't follow that they exist at all times. The Domain is just a collection of existing items, whether they can be temporally located or not (abstract objects). If there is some time at which Socrates exists, then he is in the Domain. But he does not exist in the Domain at all times: the domain itself is not temporally ordered (either Aor B-series) - even though it contains temporal objects (like Socrates) from beginning at $470 \mathrm{BCE}$. So, on my view, the Domain-the ontology - is time-indexed (pace many other philosophers).

As Prof. Oaklander says, the complete ontology is unchanging-it is complete. Of course, but there is no complete ontology until the end of time. (This is an ontological, not an epistemic point.) However, he seems to think that temporal objects in the Domain do not exist at times. That doesn't follow. Socrates is in the Domain, and one of his properties is living from 470 until 399 BCE. The ontology changes as new things (including artifacts and artworks) come into existence. The fact that other philosophers (e.g., Sider) regard ontology as timeless, I take to be a shortcoming of their views. I am trying to offer a different view-one more suitable to understanding the world we actually encounter. Since my view has room for novelty, there is no answer in 2016 to what the Domain will contain in 2061.

I do not misunderstand ontology; I just have a different view of the collection of things that exist. Similarly, I do not think that I misunderstand mind-dependence. Rather I do not think that the mindindependence/mind-dependence distinction is fundamental. Mind- 
dependent items (concrete and abstract objects, kinds, properties) are items whose existence depends on there being creatures with minds. Moreover, I think that many mind-dependent items are ontologically significant-including those that human beings invent-even though their existence depends on there being creatures with intentions. When Gutenberg invented the printing press with movable type, he changed the course of history. Why omit an invention with such extraordinary causal powers from ontology?

Finally, I think that Prof. Oaklander is just mistaken when he says that "growth in the ontology of the temporal world... must be by the comingin-existence NOW of what did not previously exist as a temporal object." (p. 19) NOW is eliminable in this context; what's required is the cominginto-existence at $\mathrm{t}$ of something that did not exist at any $\mathrm{t}^{\prime}<\mathrm{t}$. Again, Prof. Oaklander assumes an A-theory.

\section{Part II}

1. Oaklander notes that I accept a temporal principle according to which if $\mathrm{x}$ ever precedes $\mathrm{y}$, then $\mathrm{x}$ always precedes $\mathrm{y}$ [assuming an inertial frame]. He seems to think that this principle commits me to holding that "the terms of B-facts have A-properties and change with respect to them." I do not hold that, and the temporal principle does not entail that.

2. Relatedly, Oaklander has a complicated argument to show that I am not entitled to say that the B-series is more fundamental than the A-series. He seems to think that on my view B-series facts exist "in virtue of existing at different A-series times." I think no such thing. There have been B-series facts since the beginning of the universe, but no A-series facts until there were conscious beings.

3. Oaklander misunderstands my saying that B-series facts always exist. The example I gave, which Oaklander quoted, was that "if the signing of the Declaration of Independence is later than the Lisbon earthquake, then the signing is always later than the Lisbon

Manuscrito - Rev. Int. Fil. Campinas, v. 40, n. 1, pp. 67-73, jan.-mar. 2017. 
earthquake". That doesn't give rise to any questions about when B-series facts come into existence, or about claims that B-series facts always exist.

4. Although I defined 'coming into existence' solely in B-theory terms, Oaklander gives quotes that he supposes "support the view that the ontological inventory increases as objects come into existence [YES] by becoming present or now." [NO] I never suggested that objects come into existence by becoming present or now.

5. I emphasized that the complete ontology does not exist until the end of time. What we call 'the complete ontology' at different times-say, at $\mathrm{t}$ - is just the ontology of things that exist at or before t. I never used the term 'growing block' at all. I do not endorse a growing-block universe that has any A-features. It is just a muddle to suppose that I endorse coming into existence as an Atheory event that happens now or in the present.

6. It is just a misreading to suppose that the Domain is the "ontological inventory as of NOW".

7. Oaklander implies that the A-theory is required to understand things' coming into existence at times, or the ontology's changing over time. I do not think that we need the A-series to explain object's coming into existence. (Before there were conscious beings, there was no A-series.)

8. I do not use "McTaggart's notion of the B-series" at all. Mc'Taggart did not think that time (or the B-series) was real. I'm a realist, a practical realist.

9. I do not want to avail myself of R-relations as both dynamic and not existing in time. That combination of features does not seem coherent to me.

Manuscrito - Rev. Int. Fil. Campinas, v. 40, n. 1, pp. 67-73, jan.-mar. 2017. 
10. I do not have any arguments against eternalism or against the B-series (or, as Oaklander says, against the R-theory). My "argument" against the B-series is that it is not sufficient for understanding all temporal facts.

11. Several times Oaklander says that I fail to distinguish between commonsense and "ontological analysis." Without being told, I think that one can discern a clear difference between an alert, "Hurry up, we're late," and, say, a theory of the dependence of the A-series on conscious beings. I consider the latter a metaphysical theory, not an analysis.

12. Since I do not think that my view of time has been correctly construed by Oaklander, I still see no reason to trade it in for an Rtheory. 